\title{
Incidence of asthma among workers exposed to sulphur dioxide and other irritant gases
}

\author{
E. Andersson*, A. Knutsson\#, S. Hagberg*, T. Nilsson", B. Karlsson+, \\ L. Alfredsson ${ }^{\S}$ and K. Torén*
}

ABSTRACT: The aim of the present study was to investigate whether repeated peak exposure (gassings) to sulphur dioxide $\left(\mathrm{SO}_{2}\right)$ and other irritant gases increases the risk of new-onset asthma. A questionnaire was sent to 4,112 sulphite workers, of whom 1,919 completed the questionnaire and 396 completed the short-form questionnaire, which was sent out as a last reminder. A sample of 130 nonrespondents completed a telephone interview using the short-form questionnaire.

The incidence of adult-onset, physician-diagnosed asthma during employment duration was analysed in relation to exposure to $\mathrm{SO}_{2}$ and gassings giving rise to respiratory symptoms. Incidence rates, as well as incidence rate ratios with $95 \%$ confidence interval $(\mathrm{Cl})$, were calculated. Further Cox regression models were used allowing assessment of hazard ratios (HR) stratified for sex and adjusted for atopy, smoking habits and age.

The incidence rate for asthma among sulphite mill workers reporting gassings of $\mathrm{SO}_{2}$ was 6.2 out of 1,000 person-yrs, compared with 1.9 out of 1,000 person-yrs among subjects unexposed to $\mathrm{SO}_{2}$ and any gassings ( $\mathrm{HR}(95 \% \mathrm{Cl}) 4.0(2.1-7.7)$ ). Among males reporting gassings to $\mathrm{SO}_{2}$, the HR (95\% Cl) for asthma was 5.8 (2.6-13) compared with unexposed males.

In conclusion, repeated peak exposure to sulphur dioxide increased the incidence of asthma during work in sulphite pulp mills, which supports the hypothesis of irritant-induced asthma.

KEYWORDS: Gassings, irritant-induced asthma, occupational asthma, pulp and paper industry, sulphur dioxide

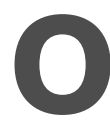
ver the last 10 yrs, several questionnairebased studies on the incidence of asthma have been published, showing an incidence of about $1-3$ cases per 1,000 person-yrs [13]. About $15 \%$ of all incident cases of asthma among adults are due to exposure in the workplace [4], and it is a well-described fact that many allergens (sensitisers) can induce occupational asthma. However, regarding exposure to irritants, such as sulphur dioxide $\left(\mathrm{SO}_{2}\right)$, ammonia and chlorine $\left(\mathrm{Cl}_{2}\right)$, the current knowledge is limited. Vast clinical experience has taught that high accidental exposures to irritants can induce asthma $[5,6]$. There is a need for better knowledge regarding the clinically important issue as to whether recurrent episodes of irritant gassing exposure (low to medium) increase the risk for asthma [7]. However, a few epidemiological studies have been published, mainly dealing with occupational exposure to $\mathrm{Cl}_{2}$ /chlorine dioxide $\left(\mathrm{ClO}_{2}\right)$ and new-onset asthma $[8,9]$. In none of these studies has the relationship between exposure to $\mathrm{SO}_{2}$ and asthma been investigated.

Regarding this research issue, case reports are of limited interest because the temporal relationship is hard to evaluate. Studies have to be designed in such a way as to make it possible to assess whether exposure increases the risk for newonset asthma. Another problem is that exposure to irritants, such as $\mathrm{SO}_{2}, \mathrm{Cl}_{2}$ or ammonia, is spread over many different occupations, making it difficult to study sufficiently large groups. However, in the pulp and paper industry, large occupational groups are exposed to $\mathrm{SO}_{2}, \mathrm{ClO}_{2}$ and ozone. In sulphite mills, where wood is pulped using an acidic method, large groups of workers are exposed to $\mathrm{SO}_{2}$. In addition to $\mathrm{SO}_{2}$, the workers may also infrequently be exposed to other irritant gases. In a previous study, sulphite mill workers were observed to have an increased mortality due to asthma, probably caused by accidental exposures to $\mathrm{SO}_{2}$ [10].

\section{AFFILIATIONS}

${ }^{*}$ Dept of Occupational and Environmental Medicine, Sahlgrenska University Hospital, Göteborg, \#Dept of Health Sciences, Mid Sweden University, and "Dept of Occupational and Environmental Medicine, Sundsvall Hospital, Sundsvall,

${ }^{+}$Dept of Occupational Medicine Dept of Clinical Medicine and Public Health, Umeå University, Umeå, and

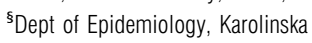
Institute, Stockholm, Sweden.

\section{CORRESPONDENCE}

E. Andersson

Dept of Occupational and Environmental Medicine

Sahlgrenska University Hospital

Box 414

SE 40530 Göteborg

Sweden

Fax: 46317733111

E-mail: Eva.Andersson@amm.gu.se

Received:

March 232005

Accepted after revision:

November 152005

SUPPORT STATEMENT

The present study was supported by the Swedish Council for Worklife

Research, Stockholm, Sweden.

European Respiratory Journal Print ISSN 0903-1936 Online ISSN 1399-3003 
Consequently, the aim of the present study was to investigate the incidence of adult-onset asthma in association with repeated peak exposures to $\mathrm{SO}_{2}$ by comparing exposed and unexposed workers within a cohort of sulphite mill workers.

\section{MATERIALS AND METHODS}

The entire cohort was identified by searching through all personnel files from four Swedish sulphite mills, where the production of pulp started in 1900, 1903, 1869 and 1960, respectively. All employees who were employed for $\geqslant 6$ months at any time between 1940 and 2000 were registered. This resulted in a cohort of 10,041 subjects. For all included subjects, information about employment time was obtained from the personnel files.

Workers employed between January 1, 1980, and July 1, 2000, and alive at the last date were eligible for this retrospective questionnaire study $(n=4,279)$. Of these, 34 could not be located, 13 died during the survey and 120 were excluded because they were aged $>80$ yrs. This left 4,112 workers eligible for the study.

In 2001, a comprehensive questionnaire titled "Work conditions and health in the pulp industry" was mailed to the 4,112 subjects. The questions had been used in previous studies [8, 11]. A last reminder included a short questionnaire, comprising the most important items. The key items from both questionnaires are listed in table 1 . The comprehensive questionnaire was answered by 1,919 subjects (47\%), whereas 396 subjects responded to the short version, giving a total response rate of $56 \%$. Among the subjects responding to the comprehensive questionnaire, 111 subjects were excluded due to incomplete answers, resulting in a population of 1,808 subjects. Basic data about the study subjects are given in table 2 .

\begin{tabular}{|c|c|}
\hline TABLE 1 & $\begin{array}{l}\text { Key items used in the short questionnaire taken } \\
\text { from the comprehensive questionnaire answered } \\
\text { by sulphite mill workers }\end{array}$ \\
\hline \multicolumn{2}{|c|}{$\begin{array}{l}\text { About exposures } \\
\text { at your work }\end{array}$} \\
\hline $4 a$ & Have you been exposed to sulphur dioxide? \\
\hline $4 \mathrm{~b}$ & If "yes", during which years? \\
\hline 5 & $\begin{array}{l}\text { Have you ever been exposed to sulphur dioxide resulting } \\
\text { in coughing, breathlessness, wheezing or pain in the } \\
\text { chest? }\end{array}$ \\
\hline 8 & $\begin{array}{l}\text { Have you ever been exposed to chlorine/chlorine dioxide } \\
\text { resulting in coughing, breathlessness, wheezing or pain } \\
\text { in the chest? }\end{array}$ \\
\hline \multicolumn{2}{|c|}{ About your health } \\
\hline $20 \mathrm{a}$ & Have you been diagnosed by a physician as having asthma? \\
\hline $20 \mathrm{~b}$ & If "yes", give the year of diagnosis? \\
\hline $23 a$ & $\begin{array}{l}\text { Have you at any time since age } 15 \text { yrs had an attack of } \\
\text { wheezing or whistling in your chest? }\end{array}$ \\
\hline $23 b$ & If "yes", in which year did you first notice it? \\
\hline $19 \mathrm{~b}$ & Have you ever had hay fever? \\
\hline \multicolumn{2}{|c|}{ About tobacco } \\
\hline 48 & Have you ever smoked daily for at least 1 yr? \\
\hline 49,50 & If so, during which years? \\
\hline
\end{tabular}

\section{Definitions}

In the present study, asthma was defined as self-reported physician-diagnosed asthma with reported onset from the age of 16 yrs. Atopy was defined as a positive response to the questions about allergy in childhood and/or hay fever. In the short questionnaire, atopy was defined as ever hay fever. Smoking was defined as daily smoking for $\geqslant 1$ yr. According to the status at follow-up, smokers were divided into current, former and never-smokers. The years of starting and stopping smoking were also obtained and used for time-dependent analysis.

Exposure to $\mathrm{SO}_{2}$ was defined as an affirmative answer to item 4a (table 1), and gassing to $\mathrm{SO}_{2}$ was defined as reported peak exposure giving rise to respiratory symptoms (item 5 ; table 1 ). Any gassings was defined as gassings to $\mathrm{SO}_{2}, \mathrm{Cl}_{2} / \mathrm{ClO}_{2}$ or gassings with any other irritant chemicals.

Unexposed subjects were those not reporting exposure to $\mathrm{SO}_{2}$ and, in addition, not reporting gassings to $\mathrm{SO}_{2}, \mathrm{Cl}_{2} / \mathrm{ClO}_{2}$ or any other irritant chemicals. Hence, the cohort was divided into three groups: group one, consisting of subjects exposed to $\mathrm{SO}_{2}$ (including those subjected to $\mathrm{SO}_{2}$ gassings); group two, consisting of subjects not reporting exposure to $\mathrm{SO}_{2}$, but reporting gassings other than with $\mathrm{SO}_{2}$; and group three, which contained unexposed subjects.

Workers employed in the digester department, where the pulping process takes place, were the most likely to be exposed to $\mathrm{SO}_{2}$. Therefore, a separate analysis on subjects reporting that they worked in a digester department was performed.

\section{Nonrespondents}

A sample of nonrespondents $(n=316)$ was randomly chosen for a telephone interview based on the short questionnaire. Of these, 130 could be reached for the interview.

\section{Statistical methods}

For all items, subjects not answering were excluded from that analysis. The main analyses were performed on the subjects answering the comprehensive questionnaire $(n=1,808)$.

Data on the year of diagnosis of asthma, time of employment and episodes of gassings allowed calculation of the incidence of asthma (during employment time plus $1 \mathrm{yr}$ ) in relation to gassings and other exposure variables. Person-yrs were calculated from each employment period (according to the personnel files) or until the year of reported diagnosis for cases. Incidence rate ratios (IRR) for asthma were calculated comparing gassed or exposed workers with unexposed workers and 95\% test-based confidence intervals (CI) were outlined [12]. To assess the impact of selection bias, additional analyses were performed with information from short questionnaires and nonrespondents included.

Hazard ratios (HR) from Cox regression models were calculated, after stratifying for sex and adjusting for atopy, time-dependent smoking status (never/former/current) and time-dependent age $\geqslant 50$ yrs.

The attributable fraction of gassings to $\mathrm{SO}_{2}$ on incident asthma among employees in sulphite pulp mills was calculated using the formula HR-1/HR. 
TABLE 2 Basic data for 1,808 sulphite mill workers employed during the period of 1980-2000

\begin{tabular}{|c|c|c|c|c|c|c|c|c|}
\hline & \multirow[t]{2}{*}{ Subjects $n$} & \multirow[t]{2}{*}{ Age yrs } & \multirow[t]{2}{*}{ Atopy \% } & \multicolumn{2}{|c|}{ Smoking habits \% } & \multirow[t]{2}{*}{ Exposed to $\mathrm{SO}_{2}$} & \multirow[t]{2}{*}{ Gassings to $\mathrm{SO}_{2} \mathrm{n}$} & \multirow[t]{2}{*}{ Asthma \% } \\
\hline & & & & Never-smokers & Current smokers & & & \\
\hline \multicolumn{9}{|l|}{$\mathbf{C Q}$} \\
\hline Males & 1548 & $48.4 \pm 13.8$ & 16.8 & 47.6 & 12.5 & 656 (42.4) & 429 & 5.6 \\
\hline Females & 260 & $42.3 \pm 11.2$ & 30.4 & 57.7 & 18.1 & $47(18.1)$ & 24 & 7.3 \\
\hline Females & 52 & $44.8 \pm 13.1$ & $17^{\#}$ & 54 & 12 & 7 (14) & 5 & 2 \\
\hline \multicolumn{9}{|c|}{ Nonrespondents } \\
\hline Males & 116 & $42.6 \pm 12.7$ & $19^{\#}$ & 49 & 16 & $34(29)$ & 23 & 5 \\
\hline Females & 14 & $40.2 \pm 16.7$ & $14^{\#}$ & 57 & 7 & $2(14)$ & 1 & 0 \\
\hline
\end{tabular}

Data are presented as $n$, mean \pm SD, \% or $n(\%)$. CQ: comprehensive questionnaire; Q: questionnaire. ${ }^{\#}$ : atopy defined as ever hay fever.

\section{RESULTS}

In total, 142 subjects reported physician-diagnosed asthma, 78 of which were excluded. The reasons for exclusion were onset of asthma before $16 \mathrm{yrs}$ of age $(n=36)$ and onset of asthma before $(n=25)$ or after $(n=17)$ employment. These exclusions left 1,730 subjects for analysis, of whom 1,489 were male. In the final population, 64 cases of asthma ( 54 males) had onset of asthma during employment time.

The incidence rate for asthma among sulphite mill workers exposed to $\mathrm{SO}_{2}$ was 4.4 per 1,000 person-yrs $(n=35)$ as compared with 1.9 per 1,000 person-yrs $(n=15)$ among subjects classified as unexposed (HR (95\% CI) 2.7 (1.4-5.1); table 3). The risk further increased among subjects reporting gassings to $\mathrm{SO}_{2}(4.0$ (2.1-7.7)) and even further among those with frequent $\mathrm{SO}_{2}$ gassings (6.8 (3.1-15)). The subgroup of workers with gassings only to $\mathrm{SO}_{2}$ also had a high risk (5.8 (2.8-12)). The group with gassings to other irritants had also an increased risk for asthma (4.6 (2.1-10.0)).

When a Cox regression model including different kinds of gassings, atopy, smoking and age, and stratified for sex, was applied to all subjects (exposed, other gassings and unexposed), the risk for asthma in relation to $\mathrm{SO}_{2}$ gassings was still high (HR (95\% CI) 4.3 (2.3-8.2)). The risk for asthma among those with "other gassings" was 2.8 (1.3-5.9). To evaluate interaction, the incidence and risk was assessed in different strata according to atopy and ever-smoking (table 4). The highest risk for asthma occurred among never-smoking workers with atopy reporting gassings.

Working in the digester area, regardless of reported irritant gas exposure, was also associated with a significant increased risk for asthma (HR (95\% CI) 4.2 (1.9-9.1)). The attributable fraction of incident asthma among sulphite mill workers due to exposure to $\mathrm{SO}_{2}$ was $63 \%$ and $75 \%$ for gassings to $\mathrm{SO}_{2}$.

Restricting the analysis to males increased the risks. Among males reporting gassings to $\mathrm{SO}_{2}$, the $\mathrm{HR}$ for asthma was 5.8 (2.6-13) compared with unexposed males.

The interview with nonrespondents was completed by 130 subjects (12.5\% of nonresponders). Analysing the complete and short questionnaires, together with the interview with nonrespondents, gave an $\mathrm{HR}$ for gassings to $\mathrm{SO}_{2}$ of 3.0 (1.85.1). The incidence rate among nonrespondents reporting exposure to $\mathrm{SO}_{2}$ was 10.6 per 1,000 person-yrs.

\section{DISCUSSION}

The most important result extracted from the present study is that repeated events of peak exposure to an irritant gas, such as $\mathrm{SO}_{2}$, causes a three-fold increased incidence of asthma. unexposed in a sulphite mill cohort

\begin{tabular}{|c|c|c|c|c|c|c|}
\hline & Subjects $n$ & Person-yrs & Cases n & Incidence & IRR (95\% CI) & $\mathrm{HR}^{+}(95 \% \mathrm{Cl})$ \\
\hline Exposed to $\mathrm{SO}_{2}$ & 674 & 8028 & 35 & 4.4 & $2.4(1.3-4.2)$ & $2.7(1.4-5.1)$ \\
\hline Gassings to $\mathrm{SO}_{2}$ & 430 & 5338 & 33 & 6.2 & $3.3(1.9-5.9)$ & $4.0(2.1-7.7)$ \\
\hline Frequent gassings to $\mathrm{SO}_{2}$ & 167 & 2252 & 20 & 8.9 & $4.8(2.6-8.8)$ & $6.8(3.1-15)$ \\
\hline Other gassings & 207 & 2087 & 14 & 6.7 & $3.6(1.8-7.1)$ & $4.6(2.1-10)$ \\
\hline Unexposed & 849 & 8086 & 15 & 1.9 & 1.0 & \\
\hline
\end{tabular}

IRR: incidence rate ratios; $\mathrm{Cl}$ : confidence interval; HR: hazard ratios. ${ }^{*}$ : employment time from mill personnel files; ${ }^{\bullet}$ : number of new cases per 1,000 person-yrs; ${ }^{+}$: stratified for sex, adjusted for atopy (proxy yes to hay fever and/or childhood allergy), time-dependent smoking status (not/quit/current), time-dependent age $\geqslant 50$ yrs. 


\begin{tabular}{|c|c|c|c|c|}
\hline \multirow{2}{*}{$\begin{array}{l}\text { TABL } \\
\text { Atopy }\end{array}$} & \multicolumn{4}{|c|}{$\begin{array}{l}\text { Incidence and risk of adult-onset asthma in } \\
\text { different strata of atopy and ever-smoking for } \\
\text { sulphite mill workers exposed to gassings to } \\
\text { sulphur dioxide }\left(\mathrm{SO}_{2}\right) \text { compared with unexposed } \\
\text { during the employment period of } 1980-2000 \\
\text { plus } 1 \mathrm{yr}\end{array}$} \\
\hline & $\begin{array}{c}\text { Ever- } \\
\text { smoking }\end{array}$ & Unexposed $^{\#}$ & Gassings to $\mathrm{SO}_{2}{ }^{\#}$ & IRR \\
\hline No & No & $1.4(4)$ & $5.3(10)$ & $3.7(1.3-11)$ \\
\hline No & Yes & $1.8(7)$ & $3.4(9)$ & $1.9(0.7-5.1)$ \\
\hline Yes & No & $4.3(3)$ & $28.5(11)$ & $6.6(2.2-20)$ \\
\hline Yes & Yes & $2.2(1)$ & $9.8(3)$ & $4.4(0.6-35)$ \\
\hline
\end{tabular}

Furthermore, $63 \%$ of all cases of new-onset asthma were caused by exposure to $\mathrm{SO}_{2}$. These results underscore the importance of preventive actions in this work environment.

The current results are based on a retrospective analysis on information gathered from a postal questionnaire. Retrospective analysis of asthma incidence is associated with less accurate recall the further back in time the analysis is applied [13]. In order to limit the magnitude of a possible recall bias, the study was restricted to the period of 1980-2000. There is a possibility that recall of asthma may differ between exposed and unexposed subjects. However, the incidence rate of adult-onset asthma found among unexposed workers in the current study (1.9 per 1,000 person-yrs) was similar to that reported for the general population in other Swedish studies $[1,3]$.

The reported year of onset for asthma may be sensitive to misclassification, meaning that a subject may report an incorrect year. The current authors are aware of two studies that validated the self-reported year of diagnosis or disease onset among subjects with asthma $[3,14]$. In the first study, $85 \%$ of subjects who reported the onset year deviated $<4$ yrs. In the second study, $90 \%$ of the subjects reported the correct year of asthma onset \pm 1 yr. In addition, there is one study in which the reliability of the temporal aspect of reported onset of asthma has been analysed. It reports a finding that $80 \%$ of the subjects correctly reported the year of asthma onset \pm 1 yr [15].

Self-reported occupational exposure data could be differentially misclassified by disease status. In a Norwegian study, the sensitivity of the question on exposure to dust and gas was biased by respiratory symptoms, but hardly at all by physician-diagnosed asthma [16], the outcome used in the present study. Bias is more important in sensitivity than it is in specificity for the effect of misclassification of exposure for a common exposure, such as the gassings in the present study [17]. Self-reporting of gassings may be sensitive to recall bias, as workers with pre-existing respiratory symptoms may be more prone to recall gassings. In the present study, among workers exposed to irritant gases, $63 \%$ of nonasthmatics reported gassings compared with $86 \%$ of subjects with childhood asthma (which were excluded in this study) and $69 \%$ of subjects with atopy but no asthma. Although the differences are slight, these figures do not indicate an obvious recall bias by disease status. Prompted questions on exposure, as in the present study, are less likely to be subject to recall bias than open-ended questions, according to a Canadian study on reliability of recall of occupational exposure [18]. In this study, work in the digester area, regardless of reported irritant exposure, was also associated with an increased risk for asthma. This further supports the present findings of a relationship between irritant gas exposure and asthma. In sulphite mills, workers are mainly exposed to $\mathrm{SO}_{2}$ but exposure to $\mathrm{Cl}_{2}$ also exists. The current authors' underlying assumption, based on interviews with process workers, is that exposed workers can distinguish between gassings to $\mathrm{SO}_{2}$ and $\mathrm{Cl}_{2} / \mathrm{ClO}_{2}$.

Possible confounding factors, such as atopy and smoking, were controlled for in the Cox regression models. Among adults $<50 \mathrm{yrs}$ of age, the incidence of asthma seems to be similar over age [1], and controlling for age $>50$ yrs in the models did not change the results. The current authors also observed that workers with atopy and reported gassings had a very high risk of asthma (table 4). This may reflect a biological interaction, i.e. subjects with atopy are more sensitive to exposure to irritating gases. However, an alternative explanation is reporting bias, i.e. workers with atopy, are more prone to report gassings due to an increased sensitivity.

Subjects reporting asthma before the start of employment were excluded, but there could still be subjects with nonidentified previous asthma. There are studies showing that subjects with asthma in remission have asymptomatic airway hyperreactivity and persistent inflammation in the airways [19, 20]. Such subjects may be at an increased risk of relapsed asthma due to exposures to gassings, which, to some extent, may explain the increased risk among subjects with atopy.

The response rate in the present study was not high; however, adding results from the late respondents (i.e. the short questionnaire) and the interviews with nonrespondents did not change the results. It has been shown that, when initial respondents are compared with all respondents, hardly any changes in prevalence and odds ratios are noted [21]. Even assuming there is no risk increase among those not responding and the same exposure frequency as among respondents, a significant risk of asthma will still be obtained (IRR (95\% CI) 2.2 (1.4-3.2) for gassings to $\mathrm{SO}_{2}$ ).

There are other studies from pulp mills showing similar results, with irritant gassings increasing the risk of asthma. In a Canadian pulp mill, the incidence of asthma among workers in the production area was 4.2 compared with 0.8 per 1,000 person-yrs among railyard workers. However, this difference was not statistically significant [22]. The main exposure in that study was $\mathrm{Cl}_{2} \mathrm{ClO}_{2}$. Gassings were not studied. In a study of bleachery workers mainly exposed to $\mathrm{Cl}_{2} \mathrm{ClO}_{2}$, the present authors found an increased incidence of asthma, 5.4 per 1,000 person-yrs compared with 1.0 among paper workers, especially among subjects reporting gassings [8]. In a large recent prospective study, including 62 USA pulp and paper mills, there was an increased incidence of asthma among 
irritant-exposed workers, of 1.4 and 3.5 per 1,000 person-yrs for males and females, respectively, compared with 1.0 and 2.0 per 1,000 person-yrs, respectively, for unexposed subjects [9]. The adjusted risk was 1.48 (1.17-1.86). Compared with the present study, gassings were more strictly defined in that study; however, the asthma outcome was less strict. Asthma was defined as "yes" answered once (there were several examinations during the study period of 1986-1998) to the question "Do you have asthma?". This outcome is less specific than physician-diagnosed asthma [11].

Occupational exposure to $\mathrm{SO}_{2}$ is common in some industries, in addition to pulp mills. Accidental occupational exposure to $\mathrm{SO}_{2}$ in a pyrite mine resulted in obstructive impairment of ventilatory function and persistent bronchial hyperresponsiveness at follow-up [23]. Repeated peak exposures to $\mathrm{SO}_{2}$ have also been reported in seasonal farming workers involved in apricot sulphurisation [24], and several cases of new-onset asthma were described in that group.

The risk of developing respiratory symptoms due to gassings may increase among those already exposed to gassings, as the inflammatory response due to repeated peaks may not completely disappear [25]. There is a longitudinal study from Quebec, Canada, showing that $\mathrm{Cl}_{2}$ gassings increase airway responsiveness [26, 27]. OLIN and coworkers [28-30] found increased nitric oxide in exhaled air among bleachery workers reporting ozone gassings, which may indicate chronic airway inflammation. Irritants are known to trigger inflammation through epithelial injury, but it has also been proposed that neuronal activity through neuropeptides gives rise to, and maintains, inflammation (i.e. neurogenic inflammation) in response to irritant exposure [31].

Irritant-induced asthma not occurring within $24 \mathrm{~h}$ of massive irritant exposure has rarely been recognised as being related to occupation, but the current study and other recent studies show that persons exposed to repeat peak exposures to irritant gases, such as $\mathrm{SO}_{2}, \mathrm{Cl}_{2}$ and ozone, have a considerably higher risk of new-onset asthma.

The associations observed in the present retrospective study should ideally be studied in a prospective study, with recurring health examinations and exposure assessments. However, there are great problems with catching the "gassings" with continuous personal monitoring; hence, additional methods with diaries and area samplings must be considered.

In conclusion, repeated peak exposure to sulfur dioxide giving rise to respiratory symptoms increased the incidence of asthma during work in sulphite pulp mills supporting the hypothesis of irritant-induced asthma.

\section{ACKNOWLEDGEMENTS}

The authors would like to thank M. Nordqvist for technical assistance.

\section{REFERENCES}

1 Torén K, Hermansson B-A. Incidence rate of adult-onset asthma in relation to age, sex, atopy and smoking. A Swedish population-based study of 15813 adults. Int J Tuberc Lung Dis 1999; 3: 192-197.
2 de Marco R, Locatelli F, Cerveri I, et al. Incidence and remission of asthma: a retrospective study on the natural history of asthma in Italy. J Allergy Clin Immunol 2002; 110: 228-235.

3 Torén K, Gislason T, Omenaas E, et al. Incidence of asthma and its predictors: a prospective study from Northern Europe (RHINE study). Eur Respir J 2004; 24: 942-946.

4 Balmes J, Becklake M, Blanc P, et al. American Thoracic Society Statement: Occupational contribution to the burden of airway disease. Am J Respir Crit Care Med 2003; 167: 787-797.

5 Brooks SM, Weiss MA, Bernstein IL. Reactive Airways Dysfunction Syndrome (RADS). Persistent asthma syndrome after high level irritant exposures. Chest 1985; 88: 376-384.

6 Kern DG. Outbreak of the reactive airways dysfunction syndrome after a spill of glacial acetic acid. Am Rev Respir Dis 1991; 144: 1058-1064.

7 Tarlo S. Workplace respiratory irritants and asthma. Occup Med 2000; 15: 471-483.

8 Andersson E, Olin A-C, Hagberg S, et al. Adult-onset asthma and wheeze among irritant-exposed bleachery workers. Am J Ind Med 2003; 43: 532-538.

9 Glindmeyer HW, Lefante JJ, Freyder LM, Friedman M, Weill H, Jones RN. Relationship of asthma to irritant gas exposures in pulp and paper mills. Respir Med 2003; 97: 541-548.

10 Andersson E, Nilsson T, Persson B, Wingren G, Toren K. Mortality from asthma and cancer among sulfite mill workers. Scand J Work Environ Health 1998; 24: 12-17.

11 Torén K, Brisman J, Järvholm B. Asthma and asthma-like symptoms in adults assessed by questionnaires: a literature review. Chest 1993; 104: 600-608.

12 Miettinen O. Estimability and estimation in case-referent studies. Am J Epidemiol 1976; 103: 226-235.

13 Brögger J, Eagan T, Eide GE, et al. Bias in retrospective studies of trends in asthma incidence. Eur Respir J 2004; 23: 281-286.

14 Torén K, Palmqvist M, Löwhagen O, Bakke P, Gulsvik A. Self-reported asthma was biased in relation to disease severity while reported year of asthma onset was accurate. J Clin Epidemiol 2006; 59: 90-93.

15 Brisman SJ, Järvholm BG. Occurrence of self-reported asthma among Swedish bakers. Scand J Work Environ Health 1995; 21: 487-493.

16 Bakke PS, Hanoa R, Gulsvik A. Relation of occupational exposure to respiratory symptoms and asthma in a general population sample: self-reported versus interview-based exposure data. Am J Epidemiol 2001; 154: 477-483.

17 Flegal KM, Brownie C, Haas JD. The effects of exposure misclassification on estimates of relative risk. $A m J$ Epidemiol 1986; 123: 736-751.

18 Teschke K, Smith JC, Olshan AF. Evidence of recall bias in volunteered $v s$. prompted responses about occupational exposures. Am J Ind Med 2000; 38: 385-388.

19 van den Toorn LM, Overbeek SE, de Jongste JC, Leman K, Hoggsteden HC, Prins J-B. Airway inflammation is present during clinical remission of atopic asthma. Am J Respir Crit Care Med 2001; 164: 2107-2113.

20 Laprise C, Boulet L-P. Asymptomatic airway hyperresponsiveness: a three year-follow-up. Am J Respir Crit Care Med 1997; 156: 403-409. 
21 Brögger J, Bakke P, Eide GE, Gulsvik A. Contribution of follow-up of nonresponders to prevalence and risk estimates: a Norwegian respiratory health survey. Am J Epidemiol 2003; 157: 558-566.

22 Enarson DA, Johnson A, Block G, et al. Respiratory health at a pulpmill in British Columbia. Arch Environ Health 1984; 39: 325-330.

23 Piirilä PL, Nordman H, Korhonon OS, Winblad I. A thirteenyear follow-up of respiratory effects of acute exposure to sulfur dioxide. Scand J Work Environ Health 1996; 22: 191-196.

24 Koksal N, Hasanoglu HC, Gokirmak M, Yildirim Z, Gultek A. Apricot sulfurization: an occupation that induces an asthma syndrome in agricultural environments. Am J Ind Med 2003; 43: 447-453.

25 Kennedy SM, Enarson DA, Janssen RG, et al. Lung health consequences of reported accidental chlorine gas exposures among pulpmill workers. Am Rev Respir Dis 1991; 143: 74-79.

26 Gautrin D, Leroyer C, L'Archeveque J, et al. Crosssectional assessment of workers with repeated exposure to chlorine over a three year period. Eur Respir J 1995; 8 2046-2054.

27 Gautrin D, Leroyer C, Infante-Rivard C, et al. Longitudinal assessment of airway caliber and responsiveness in workers exposed to chlorine. Am J Respir Crit Care Med 1999; 160: 1232-1237.

28 Olin A-C, Ljungkvist G, Bake B, Hagberg S, Henriksson L, Toren K. Exhaled nitric oxide among pulpmill workers reporting gassing incidents involving ozone and chlorine dioxide. Eur Respir J 1999; 14: 828-831.

29 Olin A-C, Granung G, Hagberg S, et al. Respiratory health among bleachery workers exposed to ozone and chlorine dioxide. Scand J Work Environ Health 2002; 28: 117-123.

30 Olin A-C, Andersson E, Andersson M, Granung G, Hagberg S, Toren K. Prevalence of asthma and exhaled nitric oxide are increased in bleachery workers exposed to ozone. Eur Respir J 2004; 23: 87-92.

31 Nowak D. Chemosensory irritation and the lung. Int Arch Occup Environ Health 2002; 75: 326-331. 